\title{
The Diagnostics Technologies and Control of COVID-19
}

\author{
Harsh Goel $^{1(\mathbb{D})}$, Keshav Goyal ${ }^{2}(\mathbb{D})$, Pritika Baranwal ${ }^{2}$ (D), Aman Dixit ${ }^{2}$ (D), \\ Tarun Kumar Upadhyay 3,*iD, Vijay J. Upadhye 3 (D)

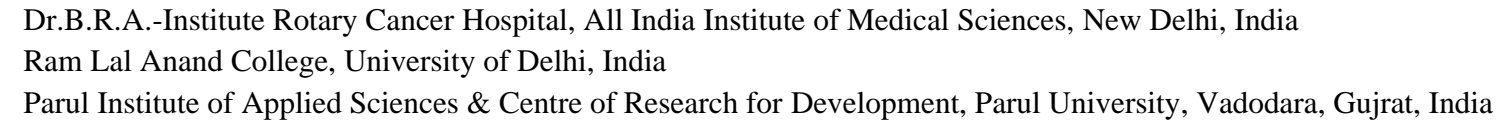

Scopus Author ID 57193549427

Received: 15.03.2021; Revised: 15.05.2021; Accepted: 20.05.2021; Published: 27.06.2021

\begin{abstract}
The coronavirus outbreak 2019 (COVID-19) is a global pandemic triggered by the extremely infectious SARS-CoV-2 virus, which is currently the world's most dreadful viral disease. Early identification, evaluation, separation, and recovery would be the most helpful ways to avoid and monitor COVID-19. After the pandemic outbreak, the reverse transcription-polymerase chain reaction (RTPCR) approach has become a common diagnostic technique of widespread clinical use. However, the extensive usage of traditional diagnostic tools in the light of COVID-19's rapid dissemination is limited by several limitations. As a result, the rapid increase in the number of COVID-19 patients necessitates the development of alternative technologies. In this regard, we summarise many advances in molecular diagnostics technologies such as nucleic acid detection-based techniques, serological systems for detecting antibodies against SARS-CoV-2, lateral flow immunoassay (LFIA), CRISPR, and metagenomics strategies that have proven to work well in COVID-19 diagnostics and may become a reliable alternative to traditional laboratories. These alternate technologies are highly resilient and precise, assisting us in making correct diagnoses and limiting the spread of COVID-19 infection. The overall conclusion of the proposed article speculates how different treatments, such as antiviral therapies, immunomodulatory therapies, Convalescent Plasma Therapy (CPT), and Several Vaccinations, have been successful in the care and control of COVID-19.
\end{abstract}

Keywords: COVID-19; Diagnostics; Technologies; SARS-CoV-2.

(C) 2021 by the authors. This article is an open-access article distributed under the terms and conditions of the Creative Commons Attribution (CC BY) license (https://creativecommons.org/licenses/by/4.0/).

\section{Introduction}

Coronaviruses (CoVs) have triggered three large pathogenic zoonotic disease outbreaks over the last two decades [1-4]. Coronaviruses belongs to the Coronaviridae family, which further comprises of four genera such as: Alphacoronavirus, Betacoronavirus, Gammacoronavirus, and Deltacoronavirus [5]. Coronaviruses belong to the positive-sense single-stranded RNA virus family [6]. Coronavirus (CoV) infections have been related to unprecedented epidemic outbreaks in East Asia and the Middle East. Severe acute respiratory syndrome coronavirus (SARS-CoV) infected 8,000 patients in 2002, with a $10 \%$ mortality rate, while Middle East respiratory syndrome coronavirus (MERS-CoV) emerge in 2002, with 2,300 cases and a 35\% mortality rate [7]. SARS stands for Severe Acute Respiratory Syndrome. SARS-CoV-2 is a modern strain of Betacoronavirus that is causing coronavirus disease 2019 (COVID-19 [8]. The World Health Organisation has declared the SARS CoV-2 and the subsequent COVID-19 epidemic a Public Health Emergency of International Significance [9]. 
SARS-CoV-2 reaches cells by identifying the spike glycoprotein on the exterior of the virus envelope of angiotensin-converting enzyme 2 (ACE2) receptors [10,11]. Following binding, the human transmembrane protease serine 2 (TMPRSS2) divides and stimulates the spike protein, triggering a conformational shift in Spike protein, which mediates viral envelope fusion with the cell membrane through endosomal pathways [12]. The viral envelope membrane bonding enables the virion to discharge genetic material within the host cell via endocytosis [13-15]. After entering a cell, the virus produces messenger RNA (mRNA), which is then converted by host ribosomal machinery to generate viral replicative enzymes, creating new RNA genomes and mRNAs to integrate the elements used construct the novel viral particles [16-19]. The viral nucleocapsid (N) protein is translated in the cytoplasm, while the structural proteins spike $(\mathrm{S})$, membrane $(\mathrm{M})$, and envelope $(\mathrm{E})$ are translated on the rough endoplasmic reticulum (RER) due to post-translation alterations. Furthermore, nucleocapsid and structural proteins are incorporated into virions particles in the ER and Golgi complexes. Finally, matured virions are delivered exterior from the host cell via exocytosis, prepared to attach with other host cells, and the process is replicated [20-22]. Multiple CoVs staying in their natural host may have preferred genetic recombination, allowing for the emergence of novel CoVs [23]. Fast-frequency mutations in CoVs occur due to the mutability of RNAdependent RNA polymerases, as well as significant frequencies of mutation and homologous RNA recombination, resulting in greater genetic diversity and the ability to infect a wide range of host species [24].

\section{Technologies for Diagnostics COVID-19}

COVID-19 clinical diagnosis is based primarily on epidemiological history, clinical symptoms, and confirmation of various laboratory tests, including CT screening, NAAT, and serology [25]. The coronavirus disease spreads rapidly by droplet particles generated by an infected person's coughing and sneezing. Asymptomatic carriers complicated the diagnosis based on COVID-19 manifestations. As a result, appropriate diagnostic methods are needed for people to mitigate and counteract rapid viral transmission. Since SARS CoV-2 is an RNAbased virus, it can be identified using any current RNA detection format. The viral genome must be reverse transcribed into a DNA complement by reverse transcriptase [26]. After the SARS COV-2 genome was sequenced entirely, the primary diagnostic technique, RT-PCR, was developed. Considering their accuracy and precision, PCR-based experiments are uneconomical and necessitate specialized equipment and technical expert assistance. As a result, it is critical to developing alternative solutions that are dependable, sensitive, and costeffective. Several methods, including CRISPR-Cas12a (AIOD-CRISPR) and FNCAS9 editorlimited standardized detection assay (FELUDA) that display positive performance in rapid COVID-19 pathogen identification, can be used to make COVID-19 diagnosis more available [27]. Diagnostic procedures are essential in the clinical treatment of COVID-19 affected patients. Various diagnostic tools assist in screening COVID-19, detecting SARS-COV-2 pathogens, and assessing the medical prognosis of COVID-19 cases, enabling public health surveillance [28]. The following technologies may be used to diagnose COVID-19 (Figure 1). 


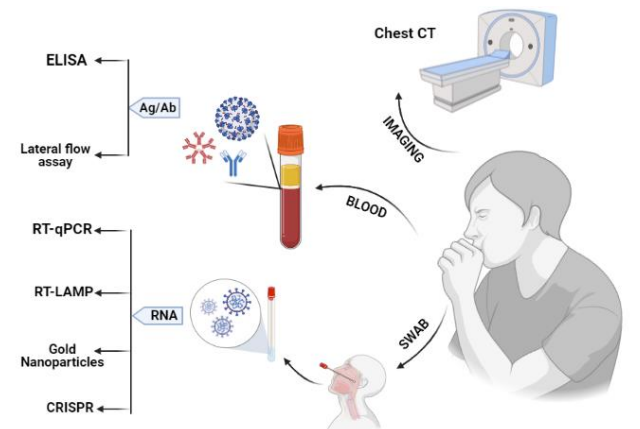

Figure 1.Various Technologies can be used for the Diagnosis of COVID-19.

\subsection{Chest Computed Tomography (CT) Scanning.}

A chest computed tomography (CT) scan is an excellent tool for identifying viral pneumonia, and it has previously been used to identify lung abnormalities in SARS and MERS situations. Chest computed tomography (CT) is initially used as a key investigative instrument for COVID-19 detection in mainland China. The chest CT results of COVID-19-infected patients indicate patchy penetration that proceeds to ground-glass opacities [29]. CT of the chest has been shown to be more vulnerable than X-rays [25,30].

\subsection{Nucleic acid amplification tests (NAAT).}

Since viremia is generally found early in the course of an outbreak, NAAT is the most sensitive and frequently used test for detecting early viral infections. Several NAAT assays, including reverse transcriptase real-time PCR (RT-PCR), reverse transcription loop-mediated isothermal amplification (RT-LAMP), microarray, and high throughput sequencing, have been established for the fast and precise diagnosis of COVID-19 [25].

\subsubsection{Reverse transcriptase real-time polymerase chain reaction (RT-PCR).}

Probe-based RT PCR assays, the gold standard tool for detecting SARS COV-2, have been used to target various genes in the SARS COV-2 genome, including S, E, N, RdRp, ORF1b, and ORF8. The E gene is targeted for SARS COV-2 screening, as recommended by WHO, accompanied by a confirmatory test targeting the rdrp gene. In comparison, the nucleocapsid protein genes N1 and N2 are endorsed by the CDC [25]. The newly established Higher sensitivity RT-PCR technology, which includes the COVID-19-RNA-dependent helicase (RdRp/Hel) assay, was susceptible and precise for detecting SARS-CoV-2 RNA in vitro and clinical specimens from the respiratory and nonrespiratory tracts, and it can help to reduce the false-negative rate among the specimens available for COVID-19 diagnosis [31].

\subsubsection{Reverse transcription loop-mediated isothermal amplification (RT-LAMP).}

Under isothermal conditions, loop-mediated isothermal amplification (LAMP), a PCRbased nucleic acid amplification process, will efficiently and quickly amplify a target series. The technique employs four to six distinct primers that recognize four to six regions on the target genome and Bst DNA polymerase, which elongates the chain at a constant temperature through strand displacement. This method can be reinforced in a regular water bath, and the enhanced product can be colored fluorescently for visualization. SARS-CoV-2 is an RNAbased virus, it necessitates reverse transcription (RT-LAMP). Several RT-LAMP tests for COVID-19 point-of-care evaluation have been validated and used since the epidemic [25]. 
2.2.3. Cartridge-based nucleic acid amplification test and TrueNAT.

Cartridge-based nucleic acid amplification test (CBNAAT) is a method for diagnosing COVID-19 that utilizes GeneXpert technology. CBNAAT device is an entirely automated PCR system that uses real-time PCR. The E gene and the N2 gene of the SARS-CoV-2 are targeted by this technique for screening and validation, respectively. TrueNAT, another nucleic acidbased procedure, targets the E gene for screening and the RdRp gene to confirm COVID-19 events. This technology allows the use of specifically chip-based devices, and testing will take up to an hour [25].

\subsection{Serology Testing.}

Since viremia is generally found early in the course of an outbreak, NAAT is the most sensitive and frequently used test for detecting early viral infections. Several NAAT assays, including reverse transcriptase real-time PCR (RT-PCR), reverse transcription loop-mediated isothermal amplification (RT-LAMP), microarray, and high throughput sequencing, have been established for the rapid and accurate diagnosis of COVID-19 [25].

\subsubsection{Antigen detection system.}

An antigen is a compound that stimulates the immune system and induces antibody formation to destroy pathogens. Unlike PCR-based techniques, antigen studies explicitly recognize viral components without the need for thermal amplification [32]. However, antigen tests, including PCR-based methods, show the status of virus infection, not the state of recovery. As opposed to nucleic acid checking, the assay had a sensitivity of $68 \%$ and an accuracy of $100 \%$. There is currently only one EUA-approved antigen test for SARS-COV-2 detection on the supply: QUIDEL's "Sofia 2 SARS Antigen Test Package" [33]. The unit employs sandwiched immunofluorescence strip technology. Following the destruction of several antibody kits, it was difficult to distinguish between two different strongly associated virus forms [34]. The WHO has not formally authorized antigen-detecting rapid diagnostic tests for medical care, but investigation through their accuracy and likely diagnostic efficiency is extremely determined [35].

\subsubsection{Antibody detection system.}

An antibody is a protein that is generated by the immune system in reaction to an antigen. Antibodies bind to just one kind of antigen in order to kill it from the body. Antibodies are classified based on their C-terminus areas. The specificity of an antibody is defined by Complementary Determining Regions (CDRs) on its $\mathrm{N}$-terminus. The $\mathrm{C}$-terminus of antibodies identifies five types: $\operatorname{IgM}, \operatorname{IgD}, \operatorname{IgG}, \operatorname{IgA}$, and $\operatorname{IgE}[36]$. $\operatorname{IgM}$ is the primary antibody generated during SARS-COV-2 infection, while IgG is the usual prevalent and rich antibody in serum. An antibody examination will detect the involvement and frequency of $\operatorname{IgG}$ and $\operatorname{IgM}$ in blood/serum/plasma samples to determine if the body is fighting the SARS-COV-2 pathogen. Antibody research is usually conducted using lateral flow assays (LFA) and enzyme-linked immunosorbent assays (ELISA) [37]. 


\subsubsection{Lateral flow type assays (LFA).}

The molecules of interest are found in the patient's blood serum through a port in lateral flow style assays (LFA). The material is collected on the sample pad, and then capillary action is used to transfer it across the strip. When they come into contact with the first hand, antibodies labeled with gold nanoparticles adhere to the target molecule in the sample. The capturing antibodies in the lines then bind the gold-labeled antibodies, and the sample goes on. Excess gold-labeled antibodies are collected at the control line as you proceed along the strip. Even if the target molecule is not present in the sample solution, the gold-labeled antibodies must be taken at the control line to ensure the test's validity [38]. Depending on if the test is for IgG- or IgM-class antibodies or both, the view window may reveal one, two, or three stripes. If the test is negative with just one kind of antibody, the control line will only display one stripe. If the evaluation and control lines each display two stripes, the outcome is positive. If both are positive, the panel will show three stripes: one on the control line, one on the $\operatorname{IgG}$ test line, and one on the IgM test line. Furthermore, an IgG/IgM examination will identify just one antibody, which may be an indirect indicator of infection development or a direct immune response [39].

\subsubsection{Enzyme-Linked Immunosorbent Assay (ELISA).}

Goal molecules for an Enzyme-Linked Immunosorbent Assay (ELISA), recombinant viral antigen, are covered onto the exteriors of plastic wells. After being processed, the sample, which is the patient's blood, is added to the wells. When antibodies such as ( $\operatorname{IgG}$ or $\operatorname{IgM})$ against the target antigen are detected in a sample, this is referred to as a binding event. The residual sample is washed out on multiple occasions to ensure that the unbound layer is discarded. Suppose the desired antibody is not included in the sample, in that case, another solution comprising labeled secondary anti-human antibodies is applied and permitted to bind. Washing removes the excess, and an enzyme-dependent color change reaction (usually horseradish peroxidase) reinforces target antibody binding. A spectrometer detects the color variation and measures the frequency of the target antibody. In chemiluminescent immunoassays (CLIA, also known as modified-ELISA), a distinct chemiluminescent substrate verifies the secondary antibody binding [40, 41].

\subsection{Gold Nanoparticles Approach for COVID-19.}

Gold nanoparticles technology is easy, fast, and sensitive, allowing for rapid quantitative detection of viruses with excellent multiplexing efficiency. To date, no study has been performed on the applications of gold nanoparticles for COVID-19. The World Nano Foundation's COVID-19 Colloidal Gold System Antibody assay is the only available testing package focused on immunochromatography for gold nanoparticles that have earned $\mathrm{CE}$ certification [42].

\subsection{Clustered regularly interspaced short palindromic repeats (CRISPR) based diagnosis.}

CRISPR (clustered regularly interspaced short palindromic repeats) is a technique for finding a specific piece of DNA inside a cell. Mammoth Biosciences developed the quickest SARS-CoV-2 test detection method, detecting 10-100 copies of viral RNA per microliter using a combination of RT-LAMP and a CRISPR-cas12-based strategy. This test's findings are accessible in only 40 minutes [43]. FELUDA (field-deployable nucleobase detection and 
recognition utilizing FnCas9) is a newly designed bedside assay that employs FnCas9 to detect virus nucleic acids as low as 110 femtomolar [44].

\subsection{Metagenomics Approaches.}

In conjunction with the above molecular tools, next-generation sequencing (NGS) of clinical specimens from COVID-19 contaminated patients would easily identify SARS-CoV2 and another pathogen is known to exacerbate SARS-CoV-2 symptoms. The metagenomic method will help pathogen identification and include genetic data, leading to a greater understanding of viral development, cellular epidemiology, and touch tracking. Furthermore, genetic profiling helps determine the rate of SARS-CoV-2 genetic mutations; this detail helps assess antiviral and vaccine effectiveness [25].

\section{Various Approaches for Control of COVID-19}

COVID -19 has become a nuisance for public health worldwide because it travels rapidly via droplet infection. Covid-19 was discovered in the Chinese province of Wuhan. However, owing to transport from the Chinese mainland and other areas of the planet, it quickly became a pandemic. The immediate travel bans placed by many countries could have played a critical role in preventing the global spread of SARS-CoV-2. Several modeled trials were carried out during the epidemic to determine how important travel controls limited the virus's dissemination. When the modeled studies' findings were linked to the real amount of infections that existed during a specified time frame, it was discovered that the number of infections with no travel restrictions was 70-80 percent greater than the actual number of cases of complete or partial travel prohibitions in different countries. Travel restrictions had a significant effect on global commerce and other politics, but they were the only way to deter the epidemic from spreading quickly [45]. Following the epidemic, the wildlife trade was temporarily prohibited due to the role of wild animal species in the transmission of COVID-19. A solid and brave judgment on the exchange in wild animal species is required to stop the chance of virus spread and outbreaks triggered by zoonotic spillover [46]. Although travel restrictions were enforced, domestic security initiatives included implementing lockdowns that limited people's mobility and adopting rules to avoid overcrowding in public areas such as ATMs, grocery stores, and markets. According to research, households have a higher transmission rate of about $6 \%$ relative to 1.2 percent for social connections with informal contacts [47].

SARS-CoV-2 contamination has been transmitted from person to person mainly via droplets or direct touch. Face masks and other personal protective equipment (PPE) may help avoid COVID-19 respiratory infections. When taking public transportation, facial masks protect against infectious aerosols and limit disease transmission to other susceptive people [48]. The average size of an aerosol is less than 5um, whereas droplet sizes vary from 5-10um; droplets infect the surface, while aerosols can float in the air for lengthy periods of time due to their small size increases the possibility of spread. Aerosols are prevented from being airborne by wearing masks [49]. Another valuable exercise that can help to control the emergence of respiratory diseases is hand grooming. SARS-CoV-2/COVID-19 involves high-level protocols such as comprehensive contact tracing, quarantine of confirmed infected people, and isolation of compromised individuals to ensure effective surveillance. A mixture of stringent supervision and preventive measures could stabilize the R0 number and reduce the likelihood of transmission [50]. Rather than relying solely on lockout protocols to fight the pandemic virus, 
countries can prioritize alternative response approaches such as large-scale surveillance, contract tracing, and localized quarantine of recorded cases. Such prevention strategies may be successful both at the beginning of a pandemic and after the lockout is removed [51]. Lockdown should only be used to slow epidemic spread in the population and prevent the healthcare system from being encumbered. The new COVID-19 infection outbreak can be kept under limitation by introducing necessary preventive and critical steps and the early isolation of additional cases in the coming days [52]. As a consequence, foreign cooperation is crucial in preventing the epidemic from spreading further [53].

\subsection{Antiviral therapy for controlling COVID-19.}

Scientists have established antiviral methods to create new targeted anti-coronavirus medicines focused on genomics and the pathological properties of different coronaviruses [54]. As of now, over 600 clinical studies for COVID-19 medicinal treatments have been published on the website "ClinicalTrials.gov." To date, no medication has been proven to be useful in the treatment of SARS-CoV-2 infection, either curatively or preventively, based on sufficient clinical evidence [55]. Previously investigated antiviral drugs shortened the disease duration by disrupting the virus's main enzymes in the host cell, interacting with the viral cycle and lowering a viral load and viral shedding. Antiviral treatments administered immediately after signs arise can shorten the length of clinical illness and decrease infectivity by minimizing virus shedding [56]. Several drugs, including remdesivir, chloroquine, lopinavir-ritonavir, penciclovir, favipiravir, and ribavirin, have been used in COVID-19 patients [57].

\subsubsection{Remedesvir.}

Remdesivir is a monophosphoramidate nucleoside prodrug engineered to travel effectively through the cell membrane and provide the active metabolite with post-viral efficacy [58]. Remedesvir, an adenosine analog, has been shown to be a potent antiviral against a wide range of RNA viruses by embedding in latent viral RNA chains, causing premature termination [57].

\subsubsection{Chloroquine.}

Chloroquine, a commonly used antimalarial and anti-autoimmune medication, has now been shown to be a broad-spectrum antiviral agent. It prevents viral entry by interacting with the glycosylation of cellular receptors and increasing endosomal $\mathrm{pH}$, in addition to providing an immune-modulating role. Chloroquine inhibited Vero E6 cell entry as well as viral entry in $\mathrm{nCoV}$ infection after oral administration, chloroquine is widely distributed across the body, including the lung [57].

\subsubsection{Lopinavir and Ritonavir.}

Lopinavir and ritonavir, both inhibitors of HIV type-1 protease, an enzyme responsible for GAG and GAG polyprotein cleavage through bond hydrolysis, were shown to have inhibitory activity against SARS COV in a screening of licensed medicines. The combination of ritonavir and lopinavir increases their plasma half-life [58, 59]. In hospitalized adult patients with critical Covid-19, medication with lopinavir-ritonavir demonstrated a marginal benefit over standard care [59]. 


\subsubsection{Penciclovir.}

Penciclovir, a guanosine derivative, is an antiviral used to combat herpes simplex virus infections. Penciclovir binds to SARS-CoV-2 RdRp based on simulated binding studies utilizing an nsp12 homology model [58].

\subsubsection{Favipiravir.}

Favipiravir is a broad-spectrum RdRp competitive inhibitor that is a purine base analog and an oral pyrazine analog. A mutagen causes the virus to mutate lethally by accumulating multiple random point mutations $[58,60]$.

\subsubsection{Ribavirin.}

Ribavirin is a guanosine analog that inhibits the replication of RNA and DNA viruses. In conjunction with other antiviral drugs, ribavirin is an important treatment for persistent hepatitis $\mathrm{C}$ virus infections. The ribavirin structure often hinders RNA capping, relying on natural guanosine to shield RNA from degeneration [58, 61].

\subsection{Immunomodulatory therapies for controlling COVID-19.}

COVID-19 extreme cases demonstrated a decrease in the amount of suppressor, helper, regulatory, and memory helper T-cells, monocytes, eosinophils, and basophils, as well as a substantial rise in the number of leukocytes, neutrophil-lymphocyte ratio, inflammatory cytokines, and infection-related biomarkers. All of this emphasizes the importance of immunomodulatory subset diligence in detecting, evaluating, and managing COVID-19 [62]. The seriousness of the infection is aggravated further by cytokine storms, virus evasion of immune reaction, and cytopathic impact. A well-coordinated innate immune response is the first line of defense against viral infection, and its dysregulation may result in excessive inflammation and death [61, 63]. The progression of the disease in its late stages is characterized by an increase in the amounts of systemic proinflammatory cytokines and biomarkers, indicating that the chances of recovery are slim. Immune modulators can inhibit cytokines and fight the cytokine storm. Immunomodulatory medications are known as immunostimulants or immunosuppressants since they activate or inhibit different facets of the immune system, in addition to modulating it. The former can also be advised to improve the immune response to specific infections. Immunomodulatory techniques that interact with cytokine signaling can be used to reduce hyper inflammation in the third stage of COVID-19 development [63].

\subsection{Convalescent Plasma Therapy (CPT) for controlling COVID-19.}

Convalescent Plasma Therapy (CPT) has been used for a long time, ever since patients with viral infections demonstrated tolerance to supportive treatment amid large-scale epidemics. It is collected from an individual who has recently recovered from a viral illness and has the maximum amounts of neutralizing antibody titer (NAT) and polyclonal antibodies against the virus. While existing drugs are being studied and new definitive therapies are being established, both passive and active immunity has been proposed as immediate possible therapeutic alternatives. Convalescent plasma has historically been utilized to increase SARS, Ebola, H1N1, and MERS patients' survival rates, with differing outcomes. In the absence of a 
definitive clinical modality for COVID-19, CPT might be one of the most appropriate therapies at this time. According to low-quality evidence with heterogeneity, convalescent plasma therapy is correlated with a $44 \%$ decrease in mortality in COVID-19 patients [62, 63].

\subsection{Human Immunoglobulin for controlling COVID-19.}

Intravenous immunoglobulin (IVIG) comprises all immunoglobulin G subclasses extracted from pooled human plasma. Although the results of IVIG on providing immunity to viral infections, including SARS, were inconclusive, several cases of thromboembolic complications were found. Various innate immune cell activities and activation may be blocked and active components neutralized with IVIG. The adaptive immune system also has ramifications in controlling B-cell cell functions, directing effector $\mathrm{T}$ cells, and repressing inflammatory cytokines. It was also suggested that IVIG exerts anti-inflammatory effects by saturating Fc receptor binding and adding antiviral antibodies and proinflammatory cytokines. COVID-19 antibodies are likely to be present in newly produced consumer IVIG drugs, but this would rely on the donor's demographics [62].

\subsection{Interferons for controlling COVID-19.}

Interferons are cytokines that suppress viral replication while also modifying the host's immune response to viral infection. Interferons are a type of cytokine identified around 50 years ago for their antiviral properties. In addition to their antiviral properties, IFNs play a function in antiviral, antitumor, and immunomodulatory responses [62,63]. During a viral infection, IFN-I is one of the first cytokines produced. They are detected by the IFNAR receptor, located on the plasma membrane in the most significant cell types. Interferon fixation on IFNAR affects transcriptional factors' phosphorylation, including STAT1, and their relocalization to the nucleus, where they stimulate interferon-stimulated genes (ISG). They thwart viral replication and propagation through various mechanisms, including cell metabolism slowing or the secretion of cytokines that encourage adaptive immunity activation. ISGs include PRRs, which render the cell more resistant to viruses, proteins that reduce membrane fluidity, block viral egress or membrane fusion, and antivirals targeting a particular viral cycle step.

As a consequence, IFN-I is essential in the antiviral culture. MERS-CoV and SARS$\mathrm{CoV}$ have been studied in vitro and vivo with IFN-I alone or in conjunction with lopinavir/ritonavir, ribavirin, remdesivir, etc or corticosteroids. Based on the information displayed above, IFN-I seems reliable and effective for SARS-CoV-2 [64].

\subsection{Vaccines for controlling COVID-19.}

In a comparatively brief amount of time, some researchers have made substantial progress in developing new vaccines. More advanced vaccine technologies, such as DNA, RNA, subunits, and virus-like particles, have been extensively screened against SARS COV-2 $[65,66]$. The minimum criterion for any effective COVID-19 vaccine suggested by WHO in its goal product profile of COVID-19 vaccine is effectiveness, preferably with a point estimate of 50 percent [67]. SARS-CoV-2 vaccines have been produced, with some achieving more than 90\% COVID-19 efficiency in clinical trials [68]. The FDA authorized a lipid nanoparticleformulated nuclear-modified mRNA vaccine encoding the spike prefusion SARS-CoV-2 glycoprotein in an Emergency Usage Authorization (EUA) for the Pfizer-BioNTech vaccine 
COVID-19 on December 11, 2020 [69]. Some authorized/approved COVID-19 vaccines include Pfizer's Comirnaty, Moderna's COVID19 Vaccine (mRNA-1273), and AstraZeneca's (AZD1222), also known as Covishield, produced by Oxford University and AstraZeneca. Gamaleya Research Institute created Sputnik V, a recombinant adenovirus vaccine (rAd26 and rAd5), and Sinovac Biotech developed CoronaVac, an inactivated vaccine [70].

\section{Conclusions}

COVID-19 is an evolving infectious disease of global public health significance that requires fast and effective detection to avoid transmission and enhance health outcomes. In this study, we looked at how Chest Computed Tomography (CT) Scanning, Nucleic acid amplification tests (NAAT) assays, Serology Immunoassays, Metagenomics, and Clustered regularly interspaced short palindromic repeats (CRISPR) can aid with the screening and diagnosis of COVID-19. Travel limits, the usage of facial masks, personal protective equipment (PPE), and hand hygiene will also help minimize the spread of COVID-19. To date, no drug has been effective in the treatment of SARS-CoV-2 infection; hence, we summarise several therapeutic medications, including remdesivir, chloroquine, lopinavir-ritonavir, penciclovir, favipiravir, and ribavirin, immunomodulatory therapies, Convalescent Plasma Therapy (CPT), Multiple Immunoglobulin, Interferons, and vaccines, that can help in the prevention and control of Covid-19.

\section{Funding}

This research received no external funding.

\section{Acknowledgments}

Authors are thankful to the Dr. Geetika Madan Patel, Medical Director, Centre of Research for Development cell, Parul University, Vadodara, Gujrat, India, and Dr.B.R.A. Institute Rotary Cancer Hospital, All India Institute of Medical Sciences, New Delhi, India, for encouragement and support for joint publication.

\section{Conflicts of Interest}

The authors declare no conflict of interest.

\section{References}

1. Cui, J.; Li, F.; Shi, Z. L. Origin and evolution of pathogenic coronaviruses. Nat Rev Microbiol 2019,17, 181192, https://doi.org/10.1038/s41579-018-0118-9.

2. De Wit, E.; Van Doremalen, N.; Falzarano, D.; Munster, V. J. SARS and MERS: recent insights into emerging coronaviruses. Nat Rev Microbiol 2016,14, 523, https://doi.org/10.1038/nrmicro.2016.81.

3. Liu, Y.; Yang, Y.; Zhang, C.; Huang, F.; Wang, F.; Yuan, J.; Wang, Z.; Li, J.; Li, J.; Feng, C.; Zhang, Z.; Wang, L.; Peng, L.; Chen, L.; Qin, Y.; Zhao, D.; Tan, S.; Yin, L.; Xu, J.; Zhou, C.; Jiang, C.; Liu. L. Clinical and biochemical indexes from 2019-nCoV infected patients linked to viral loads and lung injury. Science China Life Sciences 2020,63, 364-374,https://doi.org/10.1007/s11427-020-1643-8.

4. Wu, A.; Peng, Y.; Huang, B.; Ding, X.; Wang, X.; Niu, P.; Meng, J.; Zhu, Z.; Zhang, Z.; Wang, J.; Sheng, J.; Quan, L.; Xia, Z.; Tan, W.; Cheng, G.; Jiang, T. Genome composition and divergence of the novel coronavirus (2019-nCoV) originating in China. Cell host \& microbe 2020,27, 325-328, https://doi.org/10.1016/j.chom.2020.02.001. 
5. Brian, D.; Baric, R. Coronavirus genome structure and replication. Coronavirus replication and reverse genetics 2005, 1-30, https://doi.org/10.1007/3-540-26765-4_1.

6. Hofmann, H.; Pohlmann, S. Cellular entry of the SARS coronavirus. Trends in microbiology 2004,12, 466472, https://doi.org/10.1016/j.tim.2004.08.008.

7. Graham, R. L.; Baric, R. S. Recombination, reservoirs, and the modular spike: mechanisms of coronavirus cross-species transmission. Journal of virology 2010,84, 3134-3146, https://doi.org/10.1128/JVI.01394-09.

8. Wong, N. A.; Saier, M. H. The SARS-Coronavirus Infection Cycle: A Survey of Viral Membrane Proteins, Their Functional Interactions and Pathogenesis. International Journal of Molecular Sciences 2021,22, 1308, https://doi.org/10.3390/ijms22031308.

9. Hachfi, W.; Lasfar, N. B. COVID-19: main therapeutic options. La Tunisie medicale 2020,98, $299-303$.

10. Luan, J.; Lu, Y.; Jin, X.; Zhang, L. Spike protein recognition of mammalian ACE2 predicts the host range and an optimized ACE2 for SARS-CoV-2 infection. Biochemical and biophysical research communications 2020,526, 165-169, https://doi.org/10.1016/j.bbrc.2020.03.047.

11. Wrapp, D.; Wang, N.; Corbett, K. S.; Goldsmith, J. A.; Hsieh, C.-L.; Abiona, O.; Graham, B. S.; McLellan, J. S. Cryo-EM structure of the 2019-nCoV spike in the prefusion conformation. Science 2020,367, 12601263, https://doi.org/10.1126/science.abb2507.

12. Hoffmann, M.; Kleine-Weber, H.; Schroeder, S.; Krüger, N.; Herrler, T.; Erichsen, S.; Schiergens, T.S.; Herrler, G.; Wu, N.-H.; Nitsche, A.; Muller, M.A.; Drosten, C.; Pohlmann, S. SARS-CoV-2 cell entry depends on ACE2 and TMPRSS2 and is blocked by a clinically proven protease inhibitor. Cell 2020, 181, 271-280, https://doi.org/10.1016/j.cell.2020.02.052.

13. Yang, N.; Shen, H.-M. Targeting the endocytic pathway and autophagy process as a novel therapeutic strategy in COVID-19. International journal of biological sciences 2020, 16, 1724, https://doi.org/10.7150/ijbs.45498.

14. Xia, S.; Zhu, Y.; Liu, M.; Lan, Q.; Xu, W.; Wu, Y.; Ying, T.; Liu, S.; Shi, Z.; Jiang, S.; Lu, L. Fusion mechanism of 2019-nCoV and fusion inhibitors targeting HR1 domain in spike protein. Cellular \& molecular immunology 2020, 1-3, https://doi.org/10.1038/s41423-020-0374-2.

15. Kuba, K.; Imai, Y.; Rao, S.; Gao, H.; Guo, F.; Guan, B.; Huan, Y.; Yang, P.; Zhang, Y.; Deng, W.; Bao, L.; Zhang, B.; Liu, G.; Wang, Z.; Chappell, M.; Liu, Y.; Zheng, D.; Leibbrandt, A.; Wada, T.; Slutsky, A.S.; Liu, D.; Qin, C.; Jiang, C.; Penninger, J.M. A crucial role of angiotensin converting enzyme 2 (ACE2) in SARS coronavirus-induced lung injury. Nature medicine 2005,11,875-879, https://doi.org/10.1038/nm1267.

16. Gordon, D.E.; Jang, G.M.; Bouhaddou, M.; Xu, J.; Obernier, K.; O’Meara, M.J.; Guo, J.Z.; Swaney, D.L.; Tummino, T.A.; Huettenhain, R.; Kaake, R.M.; Richards, A.L.; Tutuncuoglu, B.; Foussard, H.; Batra, J.; Haas, K.; Modak, M.; Kim, M.; Haas, P.; Polacco, B.J.; Braberg, H.; Fabius, J.M.; Eckhardt, M.; Soucheray, M.; Bennett, M.J.; Cakir, M.; McGregor, M.J.; Li, Q.; Naing, Z.Z.C.; Zhou, Y.; Peng, S.; Kirby, I.T.; Melnyk, J.E.; Chorba, J.S.; Lou, K.; Dai, S.A.; Shen, W.; Shi, Y.; Zhang, Z.; Barrio-Hernandez, I.; Memon, D.; Hernandez-Armenta, C.; Mathy, C.J.P.; Perica, T.; Pilla, K.B.; Ganesan, S.J.; Saltzberg, D.J.; Ramachandran, R.; Liu, X.; Rosenthal, S.B.; Calviello, L.; Venkataramanan, S.; Liboy-Lugo, J.; Lin, Y.; Wankowicz, S.A.; Bohn, M.; Sharp, P.P.; Trenker, R.; Young, J.M.; Cavero, D.A.; Hiatt, J.; Roth, T.L.; Rathore, U.; Subramanian, A.; Noack, J.; Hubert, M.; Roesch, F.; Vallet, T.; Meyer, B.; White, K.M.; Miorin, L.; Rosenberg, O.S.; Verba, K.A.; Agard, D.; Ott, M.; Emerman, M.; Ruggero, D.; García-Sastre, A.; Jura, N.; von Zastrow, M.; Taunton, J.; Ashworth, A.; Schwartz, O.; Vignuzzi, M.; d'Enfert, C.; Mukherjee, S.; Jacobson, M.; Malik, H.S.; Fujimori, D.G.; Ideker, T.; Craik, C.S.; Floor, S.; Fraser, J.S.; Gross, J.; Sali, A.; Kortemme, T.; Beltrao, P.; Shokat, K.; Shoichet, B.K.; Krogan, N.J. A SARS-CoV-2-Human Protein-Protein Interaction Map Reveals Drug Targets and Potential Drug-Repurposing. BioRxiv 2020, https://doi.org/10.1101/2020.03.22.002386.

17. Brai, A.; Martelli, F.; Riva, V.; Garbelli, A.; Fazi, R.; Zamperini, C.; Pollutri, A.; Falsitta, L.; Ronzini, S.; Maccari, L. DDX3X helicase inhibitors as a new strategy to fight the West Nile virus infection. Journal of medicinal chemistry 2019,62, 2333-2347, https://doi.org/10.1021/acs.jmedchem.8b01403.

18. Brai, A.; Fazi, R.; Tintori, C.; Zamperini, C.; Bugli, F.; Sanguinetti, M.; Stigliano, E.; Esté, J.; Badia, R.; Franco, S.; Martinez, M.A.; Martinez, J.P.; Meyerhans, A.; Saladini, F.; Zazzi, M.; Garbelli, A.; Maga, G.; Botta, M. Human DDX3 protein is a valuable target to develop broad spectrum antiviral agents. Proceedings of the National Academy of Sciences 2016,113, 5388-5393, https://doi.org/10.1073/pnas.1522987113.

19. Romano, M.; Ruggiero, A.; Squeglia, F.; Maga, G.; Berisio, R. A structural view of SARS-CoV-2 RNA replication machinery: RNA synthesis, proofreading and final capping. Cells 2020,9, 1267, https://doi.org/10.3390/cells9051267. 
20. Shereen, M. A.; Khan, S.; Kazmi, A.; Bashir, N.; Siddique, R. COVID-19 infection: Origin, transmission, and characteristics of human coronaviruses. Journal of advanced research 2020, 24, 91-98, https://doi.org/10.1016/j.jare.2020.03.005.

21. Iqbal, H.; Romero-Castillo, K.D.; Bilal, M.; Parra-Saldivar, R. The emergence of novel-coronavirus and its replication cycle-an overview. J Pure Appl Microbiol 2020, 14, 13-16, https://doi.org/10.22207/JPAM.14.1.03.

22. Khade, S.M.; Yabaji, S.M.; Srivastava, J. An update on COVID-19: SARS-CoV-2 life cycle, immunopathology, and BCG vaccination. Preparative biochemistry \& biotechnology 2020, 1-9, https://doi.org/10.1080/10826068.2020.1848869.

23. Su, S.; Wong, G.; Shi, W.; Liu, J.; Lai, A. C.; Zhou, J.; Liu, W.; Bi, Y.; Gao, G. F. Epidemiology, genetic recombination, and pathogenesis of coronaviruses. Trends in microbiology 2016,24, 490-502, https://doi.org/10.1016/j.tim.2016.03.003.

24. Ng, O.-W.; Tan, Y.-J. Understanding bat SARS-like coronaviruses for the preparation of future coronavirus outbreaks-implications for coronavirus vaccine development. Human vaccines \& immunotherapeutics 2017,13, 186-189, https://doi.org/10.1080/21645515.2016.1228500.

25. Rai, P.; Kumar, B.K.; Deekshit, V.K.; Karunasagar, I.; Karunasagar, I. Detection technologies and recent developments in the diagnosis of COVID-19 infection. Applied Microbiology and Biotechnology 2021,105, 441-455,https://doi.org/10.1007/s00253-020-11061-5.

26. Vandenberg, O.; Martiny, D.; Rochas, O.; van Belkum, A.; Kozlakidis, Z. Considerations for diagnostic COVID-19 tests. Nature Reviews Microbiology 2020, 19, 171-183, https://doi.org/10.1038/s41579-02000461-z.

27. Islam, K.U.; Iqbal, J. An Update on Molecular Diagnostics for COVID-19. Frontiers in cellular and infection microbiology 2020,10, https://doi.org/10.3389/fcimb.2020.560616.

28. Caliendo, A.M.; Gilbert, D.N.; Ginocchio, C.C.; Hanson, K.E.; May, L.; Quinn, T.C.; Tenover, F.C.; Alland, D.; Blaschke, A.J.; Bonomo, R.A.; Carroll, K.C.; Ferraro, M.J.; Hirschhorn, L.R.; Joseph, W.P.; Karchmer, T.; MacIntyre, A.T.; Reller, L.B.; Jackson, A.F.; for the Infectious Diseases Society of, A. Better Tests, Better Care: Improved Diagnostics for Infectious Diseases. Clin. Infect. Dis. 2013, 57, S139-S170, https://doi.org/10.1093/cid/cit578.

29. Zhang, J.; Zhou, L.; Yang, Y.; Peng, W.; Wang, W.; Chen, X. Therapeutic and triage strategies for 2019 novel coronavirus disease in fever clinics. The Lancet Respiratory Medicine 2020,8, e11-e12, https://doi.org/10.1016/S2213-2600(20)30071-0.

30. Wong, H.Y.F.; Lam, H.Y.S.; Fong, A.H.-T.; Leung, S.T.; Chin, T.W.-Y.; Lo, C.S.Y.; Lui, M.M.-S.; Lee, J.C.Y.; Chiu, K.W.-H.; Chung, T.W.-H.; Lee, E.Y.P.; Wan, E.Y.F.; Hung, I.F.N.; Lam, T.P.W.; Kuo, M.D.; Ng, M.-Y. Frequency and Distribution of Chest Radiographic Findings in Patients Positive for COVID-19. Radiology 2020, 296, E72-E78, https://doi.org/10.1148/radiol.2020201160.

31. Chan, J.F.-W.; Yip, C.C.-Y.; To, K.K.-W.; Tang, T.H.-C.; Wong, S.C.-Y.; Leung, K.-H.; Fung, A.Y.-F.; Ng, A.C.-K.; Zou, Z.; Tsoi, H.-W.; Choi, G.K.-Y.; Tam, A.R.; Cheng, V.C.-C.; Chan, K.-H.; Tsang, O.T.-Y.; Yuen, K.-Y. Improved molecular diagnosis of COVID-19 by the novel, highly sensitive and specific COVID19-RdRp/Hel real-time reverse transcription-PCR assay validated in vitro and with clinical specimens. Journal of clinical microbiology 2020,58, e00310-20,https://doi.org/10.1128/JCM.00310-20.

32. Green, J.; Edgerton, J.; Naftel, D.; Shoub, K.; Cranmer, S.J. Elusive consensus: Polarization in elite communication on the COVID-19 pandemic. Science Advances 2020,6, eabc2717, https://doi.org/10.1126/sciadv.abc2717.

33. Goel, H.; Gupta, I.; Mourya, M.; Gill, S.; Chopra, A.; Ranjan, A.; Rath, G.K.; Tanwar, P. A systematic review of clinical and laboratory parameters of 3,000 COVID-19 cases. Obstetrics \& Gynecology Science 2021,64, 174-189, https://doi.org/10.5468/ogs.20174.

34. McAndrews, P.J. COVID-19 Task Force Updates. International Society of Hair Restoration Surgery 2020,30, 91-91, https://doi.org/10.33589/30.3.91a.

35. Peeling, R. W.; Wedderburn, C. J.; Garcia, P. J.; Boeras, D.; Fongwen, N.; Nkengasong, J.; Sall, A.; Tanuri, A.; Heymann, D.L. Serology testing in the COVID-19 pandemic response. The Lancet Infectious Diseases 2020, 20, e245-e249, https://doi.org/10.1016/S1473-3099(20)30517-X.

36. Jacofsky, D.; Jacofsky, E. M.; Jacofsky, M. Understanding antibody testing for COVID-19. The Journal of arthroplasty 2020,35, S74-S81,https://doi.org/10.1016/j.arth.2020.04.055. 
37. Loeffelholz, M.J.; Tang, Y.-W. Laboratory diagnosis of emerging human coronavirus infections-the state of the art. Emerging microbes \& infections 2020,9,747-756, https://doi.org/10.1080/22221751.2020.1745095.

38. Soh, J.H.; Chan, H.-M.; Ying, J.Y. Strategies for developing sensitive and specific nanoparticle-based lateral flow assays as point-of-care diagnostic device. Nano Today 2020,30,100831, https://doi.org/10.1016/j.nantod.2019.100831.

39. Yuce, M.; Filiztekin, E.; Ozkaya, K. G. COVID-19 diagnosis-A review of current methods. Biosensors and Bioelectronics 2020, 112752, https://doi.org/10.1016/j.bios.2020.112752.

40. Omoboyowa, D.A.; Chukwudozie, O.S.; Nweze, V.N.; Saibu, O.A.; Abdulahi, A. SARS-COV-2 Spike Glycoprotein as Inhibitory Target for Insilico Screening of Natural Compounds.Biointerface Research in Applied Chemistry 2021, 11, 14974-14985, https://doi.org/10.33263/BRIAC116.1497414985.

41. Wan, D.; Luo, X.; Dong, W.; Zhang, Z. Current practice and potential strategy in diagnosing COVID-19. Eur Rev Med Pharmacol Sci 2020,24, 4548-4553, https://doi.org/10.26355/eurrev_202004_21039.

42. Younes, S.; Al-Jighefee, H.; Shurrab, F.; Al-Sadeq, D.W.; Younes, N.; Dargham, S. R.; Al-Dewik, N.; Qotba, H.; Syed, M.; Alnuaimi, A. Diagnostic Efficiency of Three Fully Automated Serology Assays and Their Correlation with a Novel Surrogate Virus Neutralization Test in Symptomatic and Asymptomatic SARSCOV-2 Individuals. Microorganisms 2021,9, 245, https://doi.org/10.3390/microorganisms9020245.

43. Broughton, J.P.; Deng, X.; Yu, G.; Fasching, C.L.; Servellita, V.; Singh, J.; Miao, X.; Streithorst, J.A.; Granados, A.; Sotomayor-Gonzalez, A.; Zorn, K.; Gopez, A.; Hsu, E.; Gu, W.; Miller, S.; Pan, C.-Y.; Guevara, H.; Wadford, D.A.; Chen, J.S.; Chiu, C.Y. CRISPR-Cas12-based detection of SARS-CoV-2. Nat. Biotechnol. 2020, 38, 870-874, https://doi.org/10.1038/s41587-020-0513-4.

44. Azhar, M.; Phutela, R.; Ansari, A.H.; Sinha, D.; Sharma, N.; Kumar, M.; Aich, M.; Sharma, S.; Rauthan, R.; Singhal, K.; Lad, H.; Patra, P.K.; Makharia, G.; Chandak, G.R.; Chakraborty, D.; Maiti, S. Rapid, fielddeployable nucleobase detection and identification using FnCas9. BioRxiv 2020, https://doi.org/10.1101/2020.04.07.028167.

45. Grepin, K.A.; Ho, T.-L.; Liu, Z.; Marion, S.; Piper, J.; Worsnop, C. Z.; Lee, K. Evidence of the effectiveness of travel-related measures during the early phase of the COVID-19 pandemic: a rapid systematic review. BMJ global health 2021,6, e004537,https://doi.org/10.1136/bmjgh-2020-004537.

46. Wang, N.; Li, S.-Y.; Yang, X.-L.; Huang, H.-M.; Zhang, Y.-J.; Guo, H.; Luo, C.-M.; Miller, M.; Zhu, G.; Chmura, A.; Hagan, E.; Zhou, J.-H.; Zhang, Y.-Z.; Wang, L.-F.; Daszak, P.; Shi, Z.-L. A. Serological evidence of bat SARS-related coronavirus infection in humans, China. Virologica Sinica 2018,33, 104-107, https://doi.org/10.1007/s12250-018-0012-7.

47. Thompson, H.A.; Mousa, A.; Dighe, A.; Fu, H.; Arnedo-Pena, A.; Barrett, P.; Bellido-Blasco, J.; Bi, Q.; Caputi, A.; Chaw, L.; De Maria, L.; Hoffmann, M.; Mahapure, K.; Ng, K.; Raghuram, J.; Singh, G.; Soman, B.; Soriano, V.; Valent, F.; Vimercati, L.; Wee, L.E.; Wong, J.; Ghani, A.C.; Ferguson, N.M. SARS-CoV-2 setting-specific transmission rates: a systematic review and meta-analysis. Clinical Infectious Diseases 2021,https://doi.org/10.1093/cid/ciab100.

48. Liu, X.; Zhang, S. COVID-19: Face masks and human to human transmission. Influenza and Other Respiratory Viruses 2020,14, 472-473, https://doi.org/10.1111/irv.12740.

49. Tabatabaeizadeh, S.-A. Airborne transmission of COVID-19 and the role of face mask to prevent it: a systematic review and meta-analysis. European Journal of Medical Research 2021,26, 1-6, https://doi.org/10.1186/s40001-020-00475-6.

50. Tang, B.; Wang, X.; Li, Q.; Bragazzi, N. L.; Tang, S.; Xiao, Y.; Wu, J. Estimation of the transmission risk of the 2019-nCoV and its implication for public health interventions. Journal of clinical medicine 2020,9, 462, https://doi.org/10.3390/jcm9020462.

51. Colbourn, T. COVID-19: extending or relaxing distancing control measures. The Lancet Public Health 2020,5, e236-e237, https://doi.org/10.1016/S2468-2667(20)30072-4.

52. Nkengasong, J. China's response to a novel coronavirus stands in stark contrast to the 2002 SARS outbreak response. Nature medicine 2020,26, 310-311, https://doi.org/10.1038/s41591-020-0771-1.

53. Wood, C. Infections without borders: a new coronavirus in Wuhan, China. British Journal of Nursing 2020,29, 166-167, https://doi.org/10.12968/bjon.2020.29.3.166.

54. Wu, C.; Liu, Y.; Yang, Y.; Zhang, P.; Zhong, W.; Wang, Y.; Wang, Q.; Xu, Y.; Li, M.; Li, X.; Zheng, M.; Chen, L.; Li, H. Analysis of therapeutic targets for SARS-CoV-2 and discovery of potential drugs by computational methods. Acta Pharmaceutica Sinica B 2020,10, 766-788, https://doi.org/10.1016/j.apsb.2020.02.008. 
55. Moussa, T.; Sabry, N. A new proposed mechanism of some known drugs targeting the SARS-CoV-2 spike glycoprotein using molecular docking. Biointerface Research in Applied Chemistry 2020,11, 12750-12760, https://doi.org/10.33263/BRIAC115.1275012760.

56. Joshi, S.; Parkar, J.; Ansari, A.; Vora, A.; Talwar, D.; Tiwaskar, M.; Patil, S.; Barkate, H. Role of favipiravir in the treatment of COVID-19. International Journal of Infectious Diseases 2020, 102, 501-508, https://doi.org/10.1016/j.ijid.2020.10.069.

57. Wang, M.; Cao, R.; Zhang, L.; Yang, X.; Liu, J.; Xu, M.; Shi, Z.; Hu, Z.; Zhong, W.; Xiao, G. Remdesivir and chloroquine effectively inhibit the recently emerged novel coronavirus (2019-nCoV) in vitro. Cell research 2020,30, 269-271, https://doi.org/10.1038/s41422-020-0282-0.

58. Simonis, A.; Theobald, S.J.; Fätkenheuer, G.; Rybniker, J.; Malin, J.J. A comparative analysis of remdesivir and other repurposed antivirals against SARS-CoV-2. EMBO molecular medicine 2021,13, e13105, https://doi.org/10.15252/emmm.202013105.

59. Cao, B.; Wang, Y.; Wen, D.; Liu, W.; Wang, J.; Fan, G.; Ruan, L.; Song, B.; Cai, Y.; Wei, M.; Li, X.; Xia, J.; Chen, N.; Xiang, J.; Yu, T.; Bai, T.; Xie, X.; Zhang, L.; Li, C.; Yuan, Y.; Chen, H.; Li, H.; Huang, H.; Tu, S.; Gong, F.; Liu, Y.; Wei, Y.; Dong, C.; Zhou, F.; Gu, X.; Xu, J.; Liu, Z.; Zhang, Y.; Li, H.; Shang, L.; Wang, K.; Li, K.; Zhou, X.; Dong, X.; Qu, Z.; Lu, S.; Hu, X.; Ruan, S.; Luo, S.; Wu, J.; Peng, L.; Cheng, F.; Pan, L.; Zou, J.; Jia, C.; Wang, J.; Liu, X.; Wang, S.; Wu, X.; Ge, Q.; He, J.; Zhan, H.; Qiu, F.; Guo, L.; Huang, C.; Jaki, T.; Hayden, F.G.; Horby, P.W.; Zhang, D.; Wang, C. A Trial of Lopinavir-Ritonavir in Adults Hospitalized with Severe Covid-19. New Engl. J. Med. 2020, 382, 1787-1799, https://doi.org/10.1056/NEJMoa2001282.

60. Zhao, H.; Zhu, Q.; Zhang, C.; Li, J.; Wei, M.; Qin, Y.; Chen, G.; Wang, K.; Yu, J.; Wu, Z., Chen, X.; Wang, G. Tocilizumab combined with favipiravir in the treatment of COVID-19: A multicenter trial in a small sample size $\quad$ Biomedicine \& Pharmacotherapy $2021,133, \quad 110825$, https://doi.org/10.1016/j.biopha.2020.110825.

61. Qin, C.; Zhou, L.; Hu, Z.; Zhang, S.; Yang, S.; Tao, Y.; Xie, C.; Ma, K.; Shang, K.; Wang, W.; Tian, D.-S. Dysregulation of immune response in patients with coronavirus 2019 (COVID-19) in Wuhan, China. Clinical infectious diseases 2020,71, 762-768,https://doi.org/10.1093/cid/ciaa248.

62. Rizk, J.G.; Kalantar-Zadeh, K.; Mehra, M.R.; Lavie, C.J.; Rizk, Y.; Forthal, D.N. Pharmacoimmunomodulatory therapy in COVID-19. Drugs 2020, 80, 1501-1503, https://doi.org/10.1007/s40265-02001396-8.

63. Sarkar, S.; Soni, K.D.; Khanna, P. Convalescent plasma is a clutch at straws in COVID-19 management! A systematic review and meta analysis. Journal of medical virology 2021,93, 11111118,https://doi.org/10.1002/jmv.26408.

64. Kline, J.N.; Kitagaki, K. Interferons. Encyclopedia of Respiratory Medicine., G.J. Laurent \& S. D. Shapiro (Eds.)., Academic Pres 2006, 346-350, https://doi.org/10.1016/B0-12-370879-6/00190-3.

65. Sallard, E.; Lescure, F.-X.; Yazdanpanah, Y.; Mentre, F.; Peiffer-Smadja, N. Type 1 interferons as a potential treatment against COVID-19. Antiviral research $2020,178, \quad 104791$, https://doi.org/10.1016/j.antiviral.2020.104791.

66. Silveira, M.M.; Moreira, G.M.S.G.; Mendonça, M. DNA vaccines against COVID-19: Perspectives and challenges. Life sciences 2020, 118919, https://doi.org/10.1016/j.lfs.2020.118919.

67. Hodgson, S.H.; Mansatta, K.; Mallett, G.; Harris, V.; Emary, K.R.; Pollard, A.J. What defines an efficacious COVID-19 vaccine? A review of the challenges assessing the clinical efficacy of vaccines against SARSCoV-2. The lancet infectious diseases 2020,21, e26-e35, https://doi.org/10.1016/S1473-3099(20)30773-8.

68. Knoll, M. D.; Wonodi, C. Oxford-AstraZeneca COVID-19 vaccine efficacy. The Lancet 2021,397, 72-74, https://doi.org/10.1016/S0140-6736(20)32623-4.

69. Oliver, S.E.; Gargano, J.W.; Marin, M.; Wallace, M.; Curran, K.G.; Chamberland, M.; McClung, N.; Campos-Outcalt, D.; Morgan, R.L.; Mbaeyi, S. The Advisory Committee on Immunization Practices' Interim Recommendation for Use of Pfizer-BioNTech COVID-19 Vaccine-United States, December 2020. Morbidity and Mortality Weekly Report 2020,69,1922-1924,https://doi.org/10.15585/mmwr.mm6950e2.

70. Doroftei, B.; Ciobica, A.; Ilie, O.-D.; Maftei, R.; Ilea, C. Mini-Review Discussing the Reliability and Efficiency of COVID-19 Vaccines. Diagnostics 2021,11,579, https://doi.org/10.3390/diagnostics11040579. 